\title{
Características epidemiológicas de Pseudomonas aeruginosa isoladas em dois laboratórios na cidade de Governador Valadares, Minas Gerais, Brasil no ano de 2018
}

\author{
Epidemiological survey of isolated Pseudomonas aeruginosa in two laboratories in the \\ city of Governador Valadares, Minas Gerais, Brazil in the year 2018
}

\section{Estudio epidemiológico de Pseudomonas aeruginosa aisladas en dos laboratórios en la ciudad de Governador Valadares, Minas Gerais, Brasil en el año 2018}

Bruna Rafaela Leão Chaves ${ }^{1}$, Camila Pancini Santos ${ }^{1}$, Cláudia Costa da Silva Paula ${ }^{1}$, Luciana Biet Venturini ${ }^{1}$, Layla Marinho Dutra Cabral ${ }^{1}$, Lourimar Viana Nascimento Franco de Sousa ${ }^{1}$, Monica Valadares Martins ${ }^{1}$, Claudia Esther Reis Godinho ${ }^{1}$, Enes Cândido Damacena Junior ${ }^{2}$, Pedro Falci Pagoto $^{2}$, Gisele Maria de Sousa ${ }^{3}$, José Mauricio Diascânio ${ }^{4}$, Elder Oliveira da Silva ${ }^{5 *}$.

\section{RESUMO}

Objetivo: Analisar a prevalência de cepas de Pseudomonas aeruginosa em dois laboratórios na cidade de Governador Valadares, Minas Gerais no ano de 2018. Métodos: Foi realizado um estudo descritivo, retrospectivo, com abordagem quantitativa. Resultados: Tiveram 148 amostras positivas para P. aeruginosa. Em relação à faixa etária predominante para o Laboratório 1 foi a de $81-90$ anos $(28 \%)$ e, para o Laboratório 2 a faixa etária que teve maior significância foi entre a compreendida entre 41-50 anos (29\%). Quanto aos sítios, destacam-se três com maior prevalência de positividade: sangue $(2,2 \%)$ e $(71,5 \%)$ nos Laboratórios 1 e 2 , respectivamente; secreções, no Laboratório $1(25,4 \%)$ e, no Laboratório 2(7,1\%). Para a urina, no Laboratório $1(42,5 \%)$ e, no Laboratório 2, $(21,4 \%)$. Quanto ao fator de resistência, constatou-se que a P. aeruginosa apresentou resistência aos antimicrobianos Amicacina, somente no Laboratório 1 (17,4\%); Cefeprime, Laboratórios 1(34,1\%) e Laboratório 2(14,2\%); Ciprofloxacino, Laboratório $1(38,1 \%)$ e Laboratório 2(21,4\%); Gentamicina, Laboratório 1(35,6\%) e Laboratório $2(21,4 \%)$; Meropenem, somente laboratório 1(27,7\%) e, Piperacilina/ Tazobactam, somente Laboratório 2 (12,5\%). Conclusão: Sugerem-se novos estudos comparativos utilizando-se de amostras laboratoriais com maior período para verificação da prevalência dessas amostras e do fluxo evolutivo das taxas de resistência.

Palavras-chave: Pseudomonas aeruginosa, Resistência, Antibacterianos, Prevalência.

\begin{abstract}
Objective: To analyze the prevalence of Pseudomonas aeruginosa strains in two laboratories in the city of Governador Valadares, Minas Gerais in 2018. Methods: Descriptive study, retrospective, with quantitative approach. Results: They had 148 positive samples for $P$. aeruginosa. The predominant age group for Laboratory 1 was $81-90$ years (28\%), and for Laboratory 2 the age group with highest significance was $41-50$ years $(29 \%)$. As for sites, three stand out with the highest prevalence of positivity: blood $(2.2 \%)$ and $(71.5 \%)$ in Laboratory 1 and 2, respectively; secretions in Laboratory 1(25.4\%) and Laboratory 2(7.1\%). For urine, in Laboratory $1(42.5 \%)$ and in Laboratory $2(21.4 \%)$. As for the resistance factor, it was found that $P$. aeruginosa showed resistance to Amicacine antimicrobials, only in Laboratory 1(17.4\%); Cefeprime, Laboratory 1(34.1\%) and Laboratory 2(14.2\%); Ciprofloxacino, Laboratory 1(38.1\%) and Laboratory 2 (21.4\%); Gentamicine, Laboratory $1(35.6 \%)$ and Laboratory $2(21.4 \%)$; Meropenem, only Laboratory $1(27.7 \%)$ and, Piperacillin / Tazobactam, only Laboratories $1(12.5 \%)$. Conclusion: Further comparative studies are suggested using laboratory samples with longer period to verify the prevalence of these samples and the evolutionary flow of resistance rates.
\end{abstract}

Keywords: Pseudomonas aeruginosa, Resistance, Anti-Bacterial Agentes, Prevalence.

1 Universidade Vale do Rio Doce - UNIVALE. Governador Valadares-MG, Brasil.

2 Secretaria Municipal de Saúde - SMS. Governador Valadares-MG, Brasil.

3 Instituto Brasileiro de Educação Superior - IBES. Governador Valadares-MG, Brasil.

${ }^{4}$ Centro Federal de Educação Tecnológica do ES, CEFET-ES, Brasil.

${ }^{5}$ Faculdade de Ciencias Médicas. Universidad Privada del Guairá - UPG. Ciudad del Este, Paraguay.

*E-mail: elder.enf@hotmail.com

SUBMETIDO EM: 9/2019

ACEITO EM: 10/2019

PUBLICADO EM: 12/2019

REAS/EJCH | Vol.11(18) | e1658 | DOI: https://doi.org/10.25248/reas.e1658.2019 Página 1 de 8 


\section{RESUMEN}

Objetivo: Analizar la prevalencia de cepas de Pseudomonas aeruginosa en dos laboratorios de la ciudad de Governador Valadares, Minas Gerais en 2018. Métodos: Estudio descriptivo, retrospectivo, con enfoque cuantitativo. Resultados: Tenían 148 muestras positivas para P. aeruginosa. El grupo de edad predominante para el Laboratorio 1 fue de 81 a 90 años (28\%), y para el Laboratorio 2 el grupo de edad con mayor significación fue de 41 a 50 años (29\%). En cuanto a los sitios, tres se destacan con la mayor prevalencia de positividad: sangre $2.2 \%$ y $71.5 \%$ en los laboratorios 1 y 2 , respectivamente; secreciones en laboratorio 1 (25.4\%) y laboratorio $2(7.1 \%)$. Para orina, en laboratorio $1(42.5 \%)$ y en laboratorio $2(21.4 \%)$. En cuanto al factor de resistencia, se encontró que $\mathrm{P}$. aeruginosa mostró resistencia a los antimicrobianos de Amicacina, solo en el laboratorio 1 17.4\%; Cefeprime, laboratorio $234.1 \%$ y laboratorios 2 14.2\%; Ciprofloxacino, laboratorio $138.1 \%$ y laboratorio 2 21.4\%; Gentamicina, laboratorio $135.6 \%$ y laboratorio 2 21.4\%; Meropenem, solo laboratorio 1 $27.7 \%$ y Piperacilina/ Tazobactam, solo laboratorio $112.5 \%$. Conclusión: Se sugieren más estudios comparativos utilizando muestras de laboratorio con un período de tiempo más largo para verificar la prevalencia de estas muestras y el flujo evolutivo de las tasas de resistencia.

Palabras clave: Pseudomonas aeruginosa, Resistencia, Antibacterianos, Prevalencia.

\section{INTRODUÇÃO}

A Pseudomonas aeruginosa (P. aeruginosa) é um bacilo gram-negativo estritamente aeróbico, não esporulado, cuja principal característica é a não utilização de carboidratos como fonte de energia pelo processo da fermentação. Desse modo, ocorre a degradação pela via oxidativa, sendo, portanto, uma bactéria não fermentadora de glicose (TEIXEIRA JOG, 2011).

Conforme descrito por Alasil SM et al. (2015), a P. aeruginosa é conhecida por causar infecções agudas caracterizadas pela produção de toxinas e infecções crônicas por meio da produção de espessa camada de biofilme. Sua patogênese está diretamente relacionada à condição do hospedeiro, afetando principalmente pacientes queimados ou com fibrose cística, internados em Unidade de Terapia Intensiva (UTI) cujo sistema imunológico está debilitado.

A bactéria é capaz de produzir diversos mecanismos de resistência frente aos antimicrobianos. De acordo com Santos IAL, et al. (2015), a bactéria define-se como um dos mecanismos para produção de enzimas $\beta$ lactamases. Estas, são capazes de inativar os antimicrobianos $\beta$-lactâmicos pela quebra do anel $\beta$-lactâmico, rompendo, assim, sua ligação amida.

Outro recurso utilizado por P. aeruginosa é a produção de bomba de fluxo que, segundo Davies e Davies (2010), é a habilidade de bombear antibióticos para fora das células, sendo está a forma mais comum de resistência à maioria das classes de antibióticos. Outra estratégia é a perda de porinas, que proporcionam a modificação nas membranas externas da bactéria, conferindo permeabilidade diminuída a diversos antibióti$\cos$ (SPLINDER A, 2009).

Segundo Neves PR, et al. (2011), a importância clínica da infecção por P. aeruginosa caracteriza-se pela expressão de múltiplas resistências aos antimicrobianos, associados a um laborioso controle da doença. De acordo com Ribeiro GES, et al. (2015), isso acarreta um alto custo terapêutico dos pacientes infectados, além do aumento da duração da hospitalização e da mortalidade.

De acordo com Guimarães DO, et al. (2010), antibióticos são compostos naturais ou sintéticos capazes de inibir o crescimento ou causar a morte de microrganismos. Esses podem ser classificados como bactericidas, quando causam a morte da bactéria, ou como bacteriostáticos, quando promovem a inibição do crescimento microbiano.

Para Blair JMA, et al. (2014), as diferentes classes de antimicrobianos $\beta$-lactâmicos desempenham atividades contra as P. aeruginosa. Fazem parte dessa classe as penicilinas, as cefalosporinas, os monobactâmicos e os carbapenêmicos.

Ainda segundo o autor, o mecanismo de ação, ou seja, o medicamento, impede a formação completa de peptídeoglicano. Esse é a responsável por formar uma estrutura rígida da parede celular bacteriana, ocorrendo assim, a lise bacteriana perdendo a sua devida estrutura. 
Neves PR, et al. (2011) citam uma importante classe de antimicrobianos direcionados ao tratamento de infecções por $P$. aeruginosa, denominados aminoglicosídeos, representados pela Amicacina e pelo Gentamicina.

O local de ação é a subunidade 30s dos ribossomas, onde o antibiótico liga-se à proteína 12s na subunidade 30s ribossômica, o que leva a um erro de leitura do código genético, evitando a produção da síntese proteica.

Foi elucidado por Nascimento T, (2015), que a classe das fluoroquinoloas, representadas pelo Ciprofloxacino, tem como alvo as enzimas que regulam o super enrolamento do ácido desoxirribonucleico (DNA) e medeiam a segregação das fitas replicadas de DNA.

Dessa forma, as fitas, posicionam-se como essenciais para o crescimento bacteriano, impedindo que exerçam suas funções o que leva a um efeito bactericida.

Diante do exposto, o artigo consistiu em analisar a prevalência de cepas de $\mathrm{P}$. aeruginosa provenientes de banco de dados disponibilizados por dois laboratórios em Governador Valadares, estado de Minas Gerais no ano de 2018.

\section{MÉTODOS}

O trabalho caracteriza-se como um estudo descritivo, retrospectivo, com abordagem quantitativa, e amostragem não-probabilística por conveniência. Foram analisadas o resultado de um total de 148 amostras coletadas em dois laboratórios da cidade de Governador Valadares/MG no ano de 2018.

Esses laboratórios correspondem a $40 \%$ das unidades laboratoriais de análises clínicas que realizam exames de antibiograma no referido município.

Utilizou-se na investigação para a apreciação dos dados envolvendo sua organização, a sumarização e detalhamento. Para cálculo estatístico foi utilizado a média aritmética. Quanto ao resumo visual e à apresentação dos dados, o trabalho utiliza-se de gráficos e de tabelas.

As variáveis dos dados avaliados constituem-se como do tipo nominal e foram categorizadas em faixa etária, sexo, sítio de coleta e fator de susceptibilidade dos antimicrobianos. Posteriormente foi elaborada uma planilha no aplicativo da Microsoft $\circledast$ Excel versão 2013, onde foram selecionadas as variáveis de interesse da pesquisa, a fim de consolidar os dados.

Em relação ao critérios éticos, por tratar-se de uma pesquisa com fonte de dados secundárias não houve necessidade de submissão ao Comitê de Ética em Pesquisa, em consonância com Resolução N. 510, de 07 de Abril de 2016, art. $1^{\circ}$, parágrafo único, Inc. v, que diz: "não serão registrada CEP/CONEP pesquisas isoladas com informações retirada de bancos de dados, cujas informações são agregadas, sem possibilidades de identificação individual".

\section{RESULTADOS E DISCUSSÕES}

Após a realização do levantamento dos dados da pesquisa, verificou-se a prevalência dessas cepas nas amostras coletadas dos pacientes pelos laboratórios.

Ressalta-se que o Laboratório 1 (Lab.1) apresenta quantitativo maior de amostras dado o seu direcionamento voltado ao atendimento de todos os pacientes hospitalizados, seja para procedimentos cirúrgicos, seja aqueles internados na UTI ou ainda para fins ambulatoriais. O Lab.1 é privado oferecendo serviços à população e a hospitais da cidade.

Já o Laboratório 2 (Lab.2) atua apenas na análise de amostras provenientes de pacientes ambulatoriais, os quais passaram por procedimento cirúrgico e estão internados no mesmo município. Nesse intuito, os indivíduos foram categorizados em grupos de acordo com a faixa etária e o respectivo laboratório onde as amostras foram coletadas, conforme o Gráfico 1. 
Gráfico 1 - Características epidemiológicas de Pseudomonas aeruginosa isoladas em dois laboratórios na cidade de Governador Valadares, Minas Gerais, Brasil no ano de 2018.

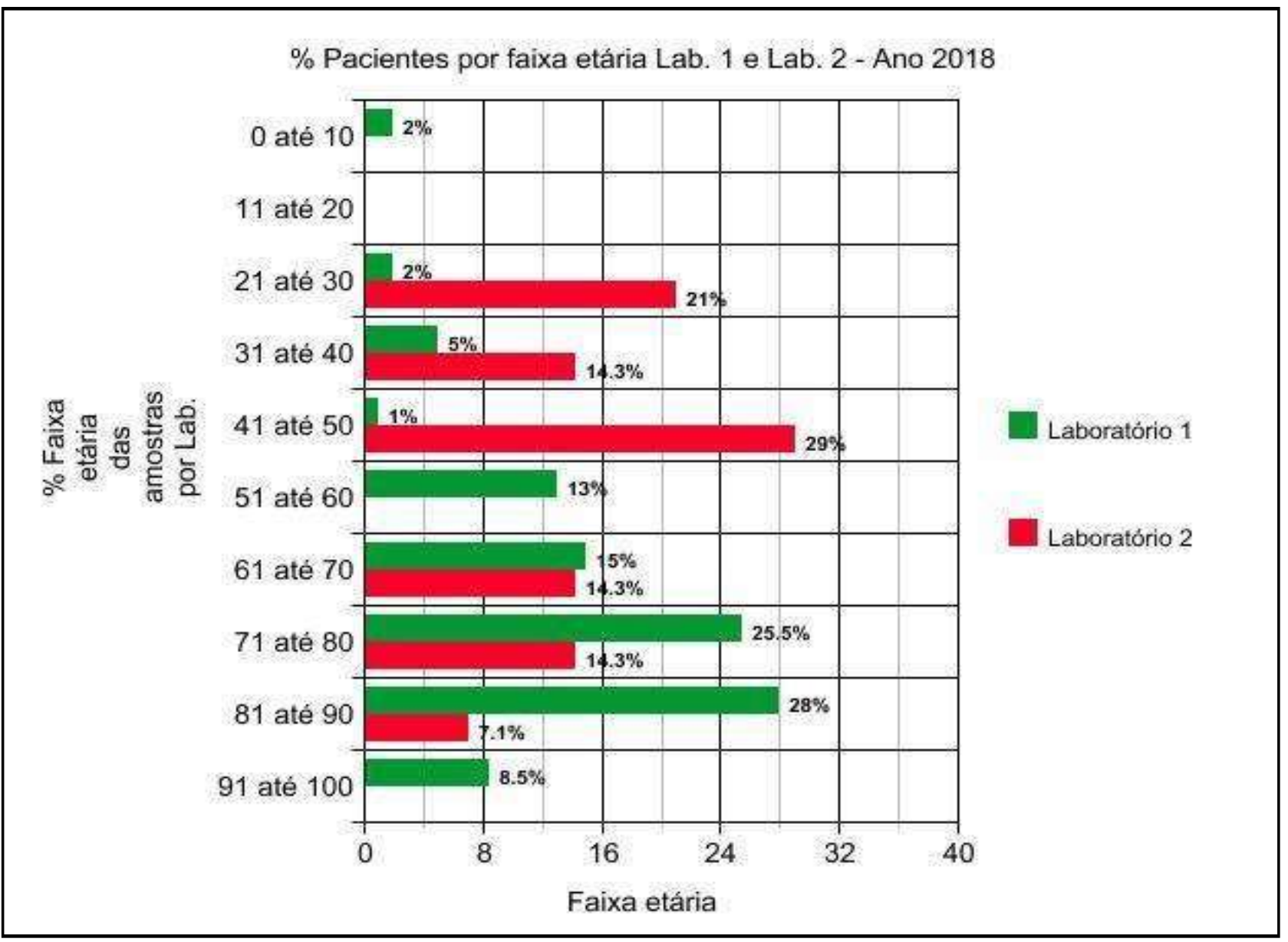

Legenda: Gráfico porcentagem de faixa etária do Laboratório 1 e do Laboratório 2.

Fonte: Chaves BRL, et al. 2018.

As faixas etárias que apresentaram valores superiores de culturas positivas para $P$. aeruginosa são de 81 até 90 anos no Lab. $128 \%$, e, no Lab. $27,1 \%$, seguida das idades 71 até 80 anos com valores do Lab.1 25,5\%, e, Lab.2 14,3\%. As idades de 21 até 50 anos apresentaram valores distintos entre os laboratórios, sendo predominante os valores do Lab. 2.

Nesse seguimento, as faixas etárias de 21 até 30 anos apresentaram os seguintes valores: Lab. $12 \%$ e Lab.2 21\%; de 31 até 40 anos Lab.1,5\% e Lab.2 14,3\%; e idades de 41 até 50 anos Lab.1 1\% e Lab.2 29\%. De modo contrastante, as idades de 61 até 70 anos apresentaram valores aproximados sendo Lab.1 15\% e Lab.2 14,3\%. Amostras de pacientes com idade de 51 até 60 e 91 até 100 anos tiveram resultados positivos somente no Lab.1, sendo eles valores de $13 \%$ e $8,5 \%$, respectivamente.

Santos AV et al. (2016) encontraram resultados superiores em relação às faixas etárias abaixo dos 60 anos, as quais apresentaram valores para a faixa-etária de 20 a 39 anos com 33,3\% e, de 40 até 59 anos, de $22,2 \%$. Porém, para a faixa etária acima de 60 anos, percebeu-se, nos estudos daquele autor, assim como no presente estudo, maior prevalência com taxa de $44,5 \%$.

Por conseguinte, os idosos apresentam maior taxa de infecção e, nesse direcionamento, Nogueira PSF et al. (2009) afirmam que eles são mais vulneráveis às infecções. Estas derivam-se de alterações fisiológicas à senilidade e pelo fato de aqueles pacientes estarem submetidos a tratamentos oncológicos, com imunossupressores, sujeitos a procedimentos cirúrgicos ou a internações em UTI, todos estes realizados em ambientes considerados críticos para infecções hospitalares. 
Para melhor interpretação dos dados, o Gráfico 2 apresenta amostras por sítios que obtiveram maior número de culturas positivas para $P$. aeruginosa. Além disso, computou-se a taxa de distribuição desses sítios entre cada laboratório, para efeito de comparação. Reforça-se que o Lab.2 não possuía amostras representativas de todos os sítios avaliados.

Observa-se um resultado significativo para amostras de sangue, 2,2\% do Lab. 1 e $71,5 \%$ do Lab.2. Desse sítio, no Lab.2 35,7\% das amostras são de hemocultura de via periférica, enquanto $28,7 \%$ são de acessos centrais. As secreções apresentaram maior índice no Lab.1 25,4\% e 7,1\% no Lab.2. Somente o Lab.2 apresentou amostras positivas num total de $15 \%$ das coletas de swabs.

Gráfico 2 - Características epidemiológicas de Pseudomonas aeruginosa isoladas em dois laboratórios na cidade de Governador Valadares, Minas Gerais, Brasil no ano de 2018.

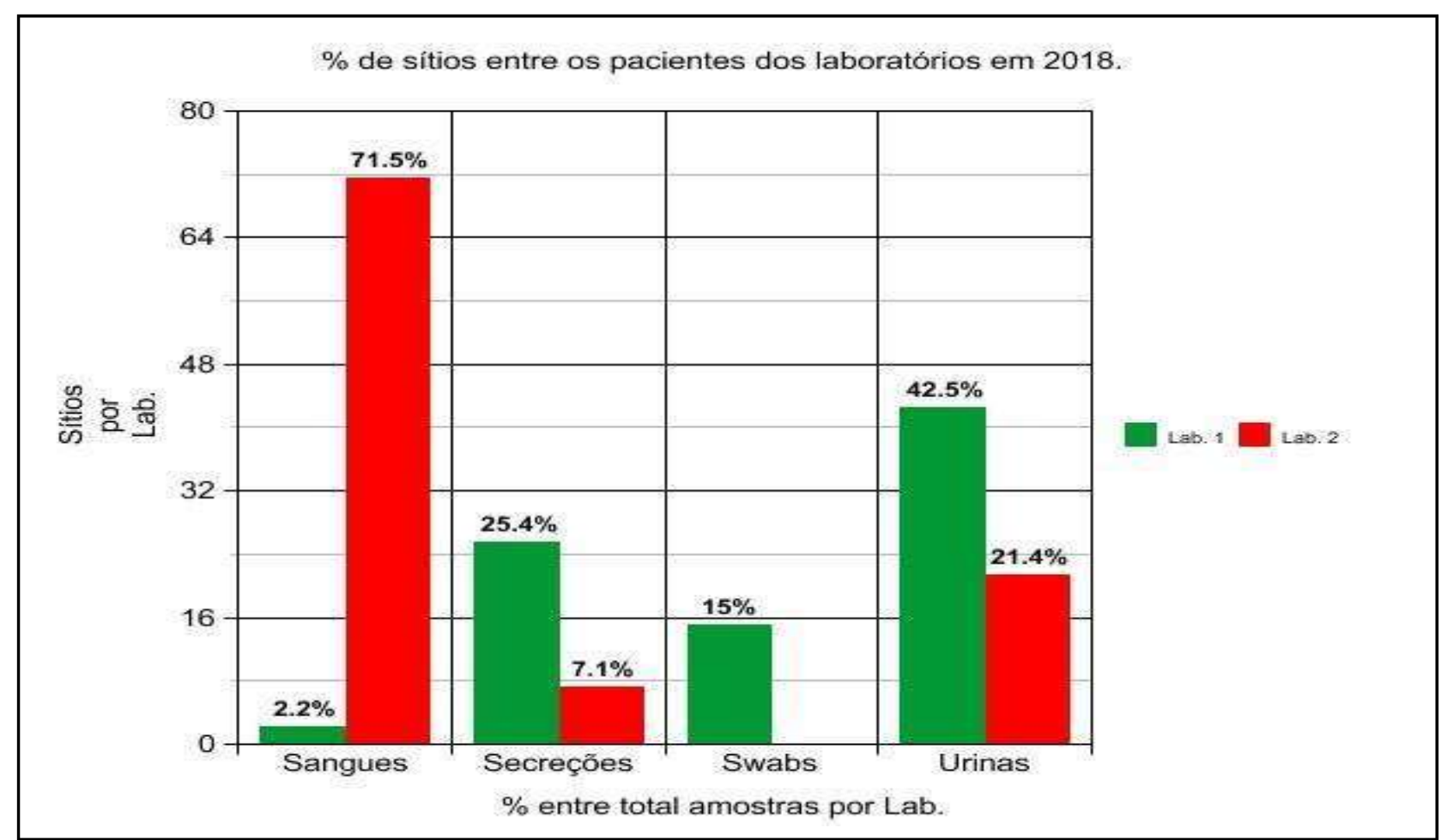

Legenda: Porcentagem de sítios do Laboratório 1 e Laboratório 2.

Fonte: Chaves BRL, et al. 2018.

Com relação à hegemonia das amostras de sangue de acessos periféricos percebe-se que este estudo corrobora com resultados encontrados no trabalho de Ruchel DB et al. (2016), no qual foram analisadas 2.832 amostras de hemoculturas de pacientes hospitalizados, sendo, desse total, identificadas somente 248 positivas. Destas, ocorreu uma prevalência dos acessos periféricos de coleta de hemoculturas, $81,4 \%$, em comparação aos resultados positivos de $16,5 \%$ nos acessos centrais.

A urina foi o sítio que apresentou o maior número de amostras positivas no Lab.2, 42,5\%, sendo estes valores superiores aos do Lab.2 21,4\%. Os resultados do Lab.2 vão ao encontro dos resultados de Garcia LM et al. (2013), que foram registrados num hospital do Norte de Minas Gerais. Em seu estudo, foram identificados 44 casos de infecções onde o sítio anatômico com maior número de infecções foi o trato urinário, com 18 casos, o equivalente a $40,9 \%$ dos casos. Destes, 10 casos, ou $5 \%$, associam- se à procedimentos invasivos com 9 casos de sonda vesical de demora e 1 caso de cateter central.

De modo complementar, cabe destacar que se considerou somente a resistência aos fármacos mais utilizados na clínica médica para o tratamento de infecções por $\mathrm{P}$. aeruginosa. Diante disso, calculou-se percentualmente a Taxa de Resistência (TR) dos antimicrobianos das amostras em que foi realizado o antibiograma apresentado no Gráfico 3. 
Gráfico 3 - Características epidemiológicas de Pseudomonas aeruginosa isoladas em dois laboratórios na cidade de Governador Valadares, Minas Gerais, Brasil no ano de 2018.

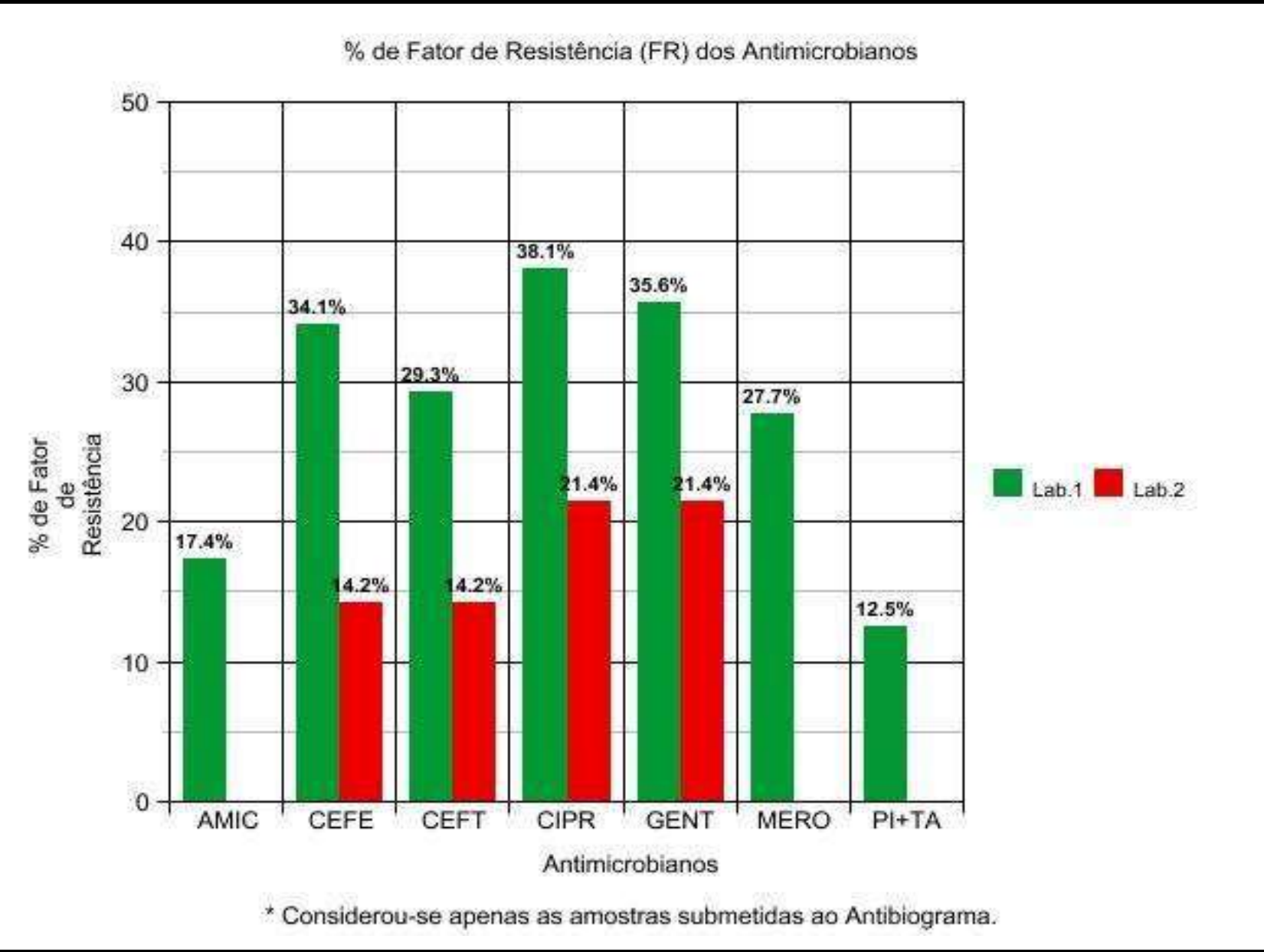

*Legenda: Aminoglicosídeos (AMIC: Amicacina, GENT: Gentamicina), Cefalosporinas (CEFE: Cefepime, CEFT Ceftazidima), Fluorquinolonas (CIPR: Ciprofloxacino), Penicilinas (PI+TA: Piperacilina/tazobactam), Carbapenêmicos (MERO: Meropenem). Fator de resistência dos antimicrobianos no Laboratório 1 e Laboratório 2.

Fonte: Chaves BRL, et al. 2018.

Segundo Costa LFR (2016), antibiograma é uma metodologia utilizada para medir a sensibilidade de microrganismos a antimicrobianos. Nesse sentido, o processo de disco de difusão configura-se como um método de prova in vitro, utilizando uma placa de Petri, onde é aplicado um disco de papel de filtro impregnado com antimicrobiano a superfície do ágar onde o microrganismo foi inoculado. Cada antimicrobiano irá formar um halo de inibição, e o diâmetro deste halo é usado na classificação do disco em Resistente. Esse método é utilizado pelos laboratórios participantes da pesquisa, seguindo as normas do Clinical and Laboratory Standards Institute (CLSI).

Segundo Motta FS et al. (2018), o tratamento empírico com antibióticos pode contribuir para uma elevada taxa de resistência aos antimicrobianos, dificultando o tratamento do paciente. Essa informação vai a favor dos estudos de Costa ALP et al. (2017), que justificam tal resistência devido ao mau uso desses fármacos, o que acelera o processo natural de resistência das bactérias contra os antibióticos.

Ainda segundo Costa ALP et al. (2017), tal resistência decorre do fato de o ambiente natural desses antimicrobianos produzir populações microbianas como ferramenta de competição por recursos nutricionais e de espaço dentro do micro-habitat que ocupam. Assim, evidencia-se que a bactéria possui uma elevada resistência ao cloridrato de Ciprofloxacino, visto que este medicamento apresentou taxa de fator de resistência de $38,1 \%$ e $21,4 \%$ nos laboratórios 1 e 2 , respectivamente. 
De modo subsequente a esse resultado, a Gentamicina, que é um aminoglicosídeo, apresentou uma taxa de resistência de $35,6 \%$ e $21,4 \%$ nos Laboratórios 1 e 2 nessa ordem. Contrariamente, a Amicacina, outro fármaco da mesma classe, por sua vez, apresentou baixo índice de resistência no Lab. 1, 17,4\%.

Segundo Carvalho MR et al. (2015), em um trabalho avaliando 56 amostras de P. aeruginosa, identificouse que o Ciprofloxacino apresentou a maior taxa de resistência entre as amostras, sendo um total de $87,5 \%$. Em seguida, de um total de 52 amostras, a Gentamicina, constitui $71,2 \%$ de resistência enquanto, por sua vez, a Amicacina exibiu um índice considerado baixo de resistência sendo 26,3\% em 38 amostras.

O Meropenem, fármaco que pertence à classe dos carbapenêmicos, evidenciou uma TR de $27,7 \%$ somente para o Lab.1 Santos SO (2014) demonstrou em seu estudo dados semelhantes, nos quais a taxa de resistência foi de $28,7 \%$. Foi elucidado por Diaz VC (2015) que os carbapenêmicos são as drogas de escolha para o tratamento de infecções hospitalares graves motivadas por uma bactéria multirresistente.

Com isso, o uso extensivo cada vez mais frequente ocasiona pressão seletiva, especialmente nas bactérias multirresistentes. Esse fenômeno possui impacto direto na escolha da terapia mais adequada, contribuindo assim para o insucesso terapêutico e, por vezes, para a morte dos pacientes.

A Piperacilina associada ao Tazobactam foi o antibiótico mais eficaz dentre os colocados sob análise, pois apresentou a menor taxa de resistência em comparação aos demais fármacos, expondo resultado positivo apenas no Lab.1. Em comparação com os estudos de Pessoa VS (2013), esta informação alinha-se ao apresentado à associação dos fármacos, sendo o fármaco com menor taxa de resistência, com apenas 120 amostras, ou $26,7 \%$.

Segundo Nazli E et al. (2014), a combinação de antibióticos mais comumente usada nas infecções $P$. aeruginosa é entre $\beta$-lactâmicos e aminoglicosídeos, o que, geralmente, apresenta um efeito sinérgico. Com isso, a antibioticoterapia combinada é geralmente administrada para o tratamento de infecções com o intuito de obter um a eficácia antibacteriana mais eficiente, retardando o desenvolvimento de resistência e reduzindo a possibilidade de efeitos colaterais.

Os antimicrobianos Cefepima e Cefttazidina, fármacos pertencentes à classe das cefalosporinas, obtiveram os resultados positivos de $34,1 \%$ e 14,2\%. Lab.1 29,3\% e 4,2\% Lab.2. A pesquisa de Machado GM et al. (2011) apresentou taxas de culturas positivas para P. aeruginosa resistentes a Ceftadizima $12,6 \%$ e Cefepima16,4\%. Estes números são inferiores se comparados aos resultados apresentados pelo Lab.1 e, quanto ao Lab.2 apresentam semelhança.

\section{CONCLUSÃO}

Após a realização do estudo, observou-se uma alta taxa de resistência da $P$. aeruginosa em relação a diversas classes de antimicrobianos. Essa resistência deveu- se ao uso inadequado dos fármacos e aos mecanismos de resistência criados pela bactéria. Observou-se um número maior de infecções nos seguintes sítios: urina, sangue e secreções. Em relação à faixa etária, identificou-se que os idosos são mais susceptíveis a infecções por, geralmente, encontrarem-se mais debilitados fisicamente. Deste modo, sugerem-se novos estudos referentes a novos tratamentos de infecções por $P$. aeruginosa, pois elas apresentam diversos fatores que reduzem a eficácia dos fármacos.

\section{REFERÊNCIAS}

1. ALASIL SM, et al. Inhibition of Quorum Sensing-Controlled Virulence Factors and Biofilm Formation in Pseudomonas aeruginosa by Culture Extract from Novel Bacterial Species of Paenibacillus Using a Rat Model of Chronic Lung Infection. International Journal of Bacteriology, Malasia, v.5, n.2, p.1-16,01jan.2015.

2. BLAIR JMA, et al. Molecular mechanisms of antibiotic resistance. Nature Reviews Microbiology, [s.I.], v. 13, n. 1, p.4251, 1 dez. 2014.

3. CARVALHO MR, et al. Incidência de bactérias multirresistentes em uma unidade de terapia intensiva. Revista Interdisciplinar, Piauí, v. 02, n. 08, p.75-85, 01 maio 2015. 
4. COSTA ALP, et al. Resistência bacteriana aos antibióticos e Saúde Pública: uma breve revisão de literatura. Estação Científica. Universidade Federal do Amapá - UNIFAP, [s.I.], v. 7, n. 2, p.45-57, 23 ago. 2017.

5. COSTA LFR. Sistema de automatização do antibiograma por disco-difusão em aplicação clínica e ambiental. Dissertação (Mestrado em Engenharia Biomédica). Programa de Pós-Graduação em Engenharia Biomédica, Faculdade Gama, Universidade de Brasília, Brasília, DF, 2016; 82p.

6. DAVIES J, DAVIES D. Origins and Evolution of Antibiotic Resistance. Microbiology and Molecular Biology Reviews, [s.l.], v. 74, n. 3, p.417-433, 30 ago. 2010. American Society for Microbiology.

7. DIAS VC. Resistência aos carbapenêmicos e virulência de Acinetobacter baumannii e Pseudomonasa eruginosa isolados de um serviço de saúde terciário. Tese (Doutorado) - Curso de Ciências Biológicas, Universidade Federal de Juiz de Fora, Juiz de Fora, 2015; $118 \mathrm{f}$.

8. GARCIA LM, et al. Perfil epidemiológico das infecções hospitalares por bactérias multidrogas resistentes em um hospital do norte de Minas Gerais. Revista de Epidemiologia e Controle de Infecção, Montes Claros, v.2, n.3, p. 4549, 07 mar. 2013.

9. GUIMARÃES DO, et al. Antibióticos: importância terapêutica e perspectivas para a descoberta e desenvolvimento de novos agentes. Química Nova, [s.I.], v. 33, n. 3, p.667-679, 2010.

10. MACHADO GM, et al. Ocorrência e perfil de sensibilidade a antimicrobianos em Pseudomonas aeruginosa e Acinetobacter sp. em um hospital terciário, no sul do Brasil. Revista da Sociedade Brasileira de Medicina Tropical, [s.I.], v. 44, n. 2, p.168-172, 1 abr. 2011.

11. MOTA FS, et a. Profile and prevalence of antimicrobial resistance of negative-Gram bacteria isolated from intensive care patients. Revista Brasileira de Análises Clínicas, [s.I.], v. 50, n. 3, p.271-277, 2018.

12. NASCIMENTO T. Ocorrência e diversidade de Bactérias gram-negativas multirresistentes em ambientes aquáticos públicos no estado de São Paulo. 2015. 32 f. Dissertação (Mestrado em Microbiologia) - Faculdade de Ciências Biológicas. Universidade de São Paulo, São Paulo, 2015; 80 pág.

13. NAZLI E, ZER Y, EKSI F. In vitro efficacy of various antibiotic combinations against Pseudomonas aeruginosa isolates. Journal of International Medical Research, Turkey, v. 5, n. 2, p.217-225, 17 jul. 2014.

14. NEVES PR, et al. Pseudomonas aeruginos a multirresistente: Um problema endêmico no Brasil. Bras Patol Med Lab, São Paulo, v. 04, n. 47, p.409-420, 20 ago. 2011.

15. NOGUEIRA PSF, et al. Perfil da infecção hospitalar em um Hospital Universitário. Revista de Enfermagem, UERJ, Fortaleza, v. 1, n. 17, p.96- 101, 06 jan. 2009.

16. PESSOA VS. Pseudomonas aeruginosa: Epidemiologia e resistência a antimicrobianos em hospital universitário do sudeste do Brasil. Dissertação (Mestrado) - Curso de Ciências em Saúde, Ciências em Saúde, Faculdade de Medicina da Universidade Federal de Uberlândia, Uberlândia, 2013; 49 f.

17. RIBEIRO GES, et al. A importância da Farmácia Clínica no uso racional de antimicrobianos em Unidade de Terapia Intensiva. Revista Brasileira de Análises Clínicas, Niterói, v. 2, n. 1, p.13-16, 01 jun. 2015.

18. RUSCHEL DB, et al. Results profile of positive blood cultures and associated factors. Revista Brasileira de Análises Clínicas, v. 49, n. 2, p.23-30, 22 set. 2016.

19. SANTOS AV, et al. Perfil das Infecções Hospitalares nas Unidades de Terapia Intensiva de um Hospital de Urgência. Revista de Enfermagem UFPE, Recife, v. 1, n. 10, p.194-201, 01 jan. 2016.

20. SANTOS IAL, et al. Mecanismos de resistência antimicrobiana em Pseudomonas aeruginosa. Revista Brasileira de Análises Clínicas Rbac, Rio de Janeiro, v. 2, n. 47, p.5-12, 13 jan. 2015.

21. SANTOS SO. Estudo de isolados clínicos de Pseudomonas aeruginosa e Acinetobacter spp. multirresistentes do Hospital Universitário de Santa Maria. Dissertação (Mestrado) - Curso de Ciências Farmacêuticas, Universidade Federal de Santa Maria, Santa Maria-RS 2014; $71 \mathrm{f}$.

22. SPINDLER A. Caracterização de cepas de Pseudomonas spp isoladas de efluente hospitalar não tratado: resistência a beta-lactâmicos e presença de integrons. Porto Alegre. Dissertação (Mestrado em Microbiologia) - Instituto de Ciências Básicas da Saúde. Universidade Federal do Rio Grande do Sul, Porto Alegre, 2009; 101p.

23. TEIXEIRA JOG. Infecção da corrente sanguínea causada por Pseudomona aeruginosa resistente aos carbapenêmicos: Fatores associados a mortalidade e influência da terapia combinada com polimixina e imipenem. Dissertação (Mestrado) - Curso de Medicina, Ciências Biológicas, Universidade Federal de São Paulo, São Paulo, 2011; 94f 